\title{
Heterogeneity of folding in Zechstein (Upper Permian) salt deposits in the Kłodawa Salt Structure, central Poland
}

\author{
Stanisław BURLIGA ${ }^{1, *}$ \\ 1 University of Wrocław, Institute of Geological Sciences, M. Borna 9, 50-204 Wrocław, Poland
}

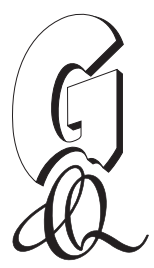

Burliga, S., 2014. Heterogeneity of folding in Zechstein (Upper Permian) salt deposits in the Kłodawa Salt Structure, central Poland. Geological Quarterly, 58 (3): 565-576, doi: 10.7306/gq.1153

\begin{abstract}
Analysis of folds carried out in the Kłodawa Salt Structure (central Poland) showed that the Upper Permian (Zechstein) siliciclastic-evaporitic succession is heterogeneously folded, resulting from differences in bed competence and stratigraphy. Rock salt and potash-rich successions of each Zechstein cycle are internally folded and contain multiple sheath folds, originated during lateral flow of salt at an early stage of deformation. These folds have been refolded by upright sheath folds within thick PZ1-PZ2 rock salt complexes. The lack of superposed folds in PZ3-PZ4 salt complexes and unconformities between the PZ1-PZ2 and PZ3-PZ4 units indicate that the rock salt beds were internally folded prior to diapirism, independently in each salt bed. The PZ1-PZ2 rock salt beds welded during lateral flow and were folded together into upright sheath folds during the upward flow of salt. These superposed folds clustered into subordinary diapirs and pierced through the younger deposits. The latter sunk in salt masses to form large-scale synclinoria, the strata of which contain early tectonic and weakly deformed sedimentary structures.
\end{abstract}

Key words: Kłodawa Salt Structure, salt tectonics, sheath folds, superposition of folds.

\section{INTRODUCTION}

Folds are among the most common tectonic structures in salt diapirs and their development is generally attributed to salt flow. There are numerous descriptions of fold shapes in rock salt diapirs, using different fold classifications, though since the 1980's most authors have concluded that folds in diapirs dominantly display sheath geometry which developed during progressive salt flow from horizontal source layers to diapiric structures (Jackson, 1985; Jackson and Cornelius, 1987; Talbot and Jackson, 1987, 1991; Jackson et al., 1990; Davison et al., 1996; Fiduk and Rowan, 2012). The complex patterns of folds observed in diapirs have been attributed to heterogeneous rates of salt flow (Kupfer, 1976, 1989) and to refolding of original recumbent sheath folds into curtain folds (Talbot and Jackson, 1987, 1989). Debate concerning the interpretation of fold geometry and history of folding in natural salt structures has resulted primarily from the limited area of fold inspection in mine galleries (e.g., Balk, 1949; Hoy et al., 1962; Kupfer, 1962; Richter-Bernburg, 1980; Talbot and Jackson, 1987; Jackson et al., 1990). Moreover, natural case studies were mostly carried out in diapirs depicting oval shapes in plan view, which had formed due to concentric supply of salt. Since the constriction of beds in an oval diapir stem during upward flow of salt leads to complex

\section{* E-mail: stanislaw.burliga@ing.uni.wroc.pl}

Received: September 27, 2013; accepted: December 25, 2013; first published online: March 7, 2014 superposition of folds (Talbot and Jackson, 1987; Jackson et al.,1990), it is extremely difficult to reconstruct the flow and folding paths of individual salt beds in such diapirs. Analogue models of salt supply to a diapiric ridge indicate that elongated salt structures are more convenient for the analysis of fold evolution. These are dominantly fed with rock salt from the flanks (Burliga et al., 2012), so the salt beds flow perpendicularly to the axis of the ridge. The supply of salt is relatively uniform along the structure and the axis of bed rotation during large scale folding is concordant with the salt ridge axis (cf. Callot et al., 2006). Such conditions enable more reliable reconstruction of folding history, owing to the known flow direction and axis of bed rotation, stable since the initiation of salt deformation. This paper provides mesostructural analysis of folds occurring within a salt wall - the Kłodawa Salt Structure, located in central Poland. It aims to restore the main stages in the evolution of folds in this diapiric structure, from their initiation to the present state.

\section{GEOLOGICAL SETTING}

The Kłodawa Salt Structure (KSS) constitutes the central part of a $60 \mathrm{~km}$ long salt ridge (the Izbica Kujawska-Kłodawa-Łęczyca salt ridge), extending NW-SE in central Poland, within the Danish-Polish Trough (Fig. 1A). Near the town of Kłodawa, Zechstein (Upper Permian) deposits pierce through the Mesozoic cover along a $\sim 30 \mathrm{~km}$ section as a salt wall, which rises from a depth of more than $6 \mathrm{~km}$ up to about $100 \mathrm{~m}$ below the ground surface (Fig. 1B). The upper section of the KSS is accessible for observation due to mine excavations cutting its uppermost part between 450 and 750 m below the surface over 


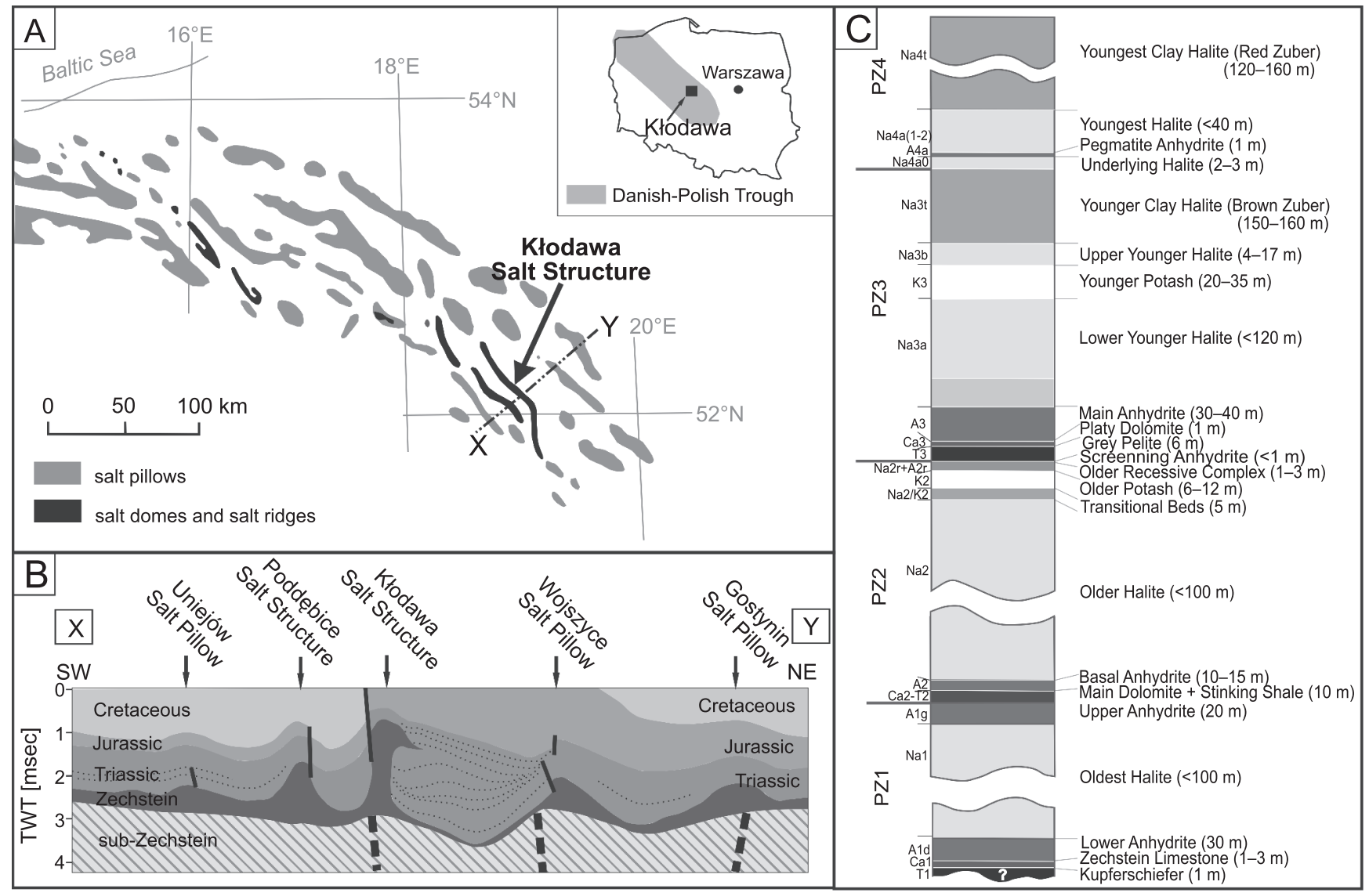

Fig. 1. The location of the Kłodawa Salt Structure and the local Zechstein stratigraphy

A - map illustrating salt structures over the area of the Zechstein Basin in Poland (after Lokhorst, 1998, modified); $\mathbf{B}$ - a regional geological cross-section based on seismic data; note basement faults beneath some salt structures and thickness variation of Mesozoic deposits on the two flanks of the KSS; dotted lines show selected horizons in Triassic deposits (interpretation after Krzywiec, 2004, 2006, modified); C schematic lithostratigraphy of Upper Permian deposits in the central part of the Polish Zechstein Basin (after Charysz, 1973; Misiek, 1997)

an area of approximately $5 \times 2 \mathrm{~km}$. The KSS is built up of Zechstein evaporitic-siliciclastic rocks of the four oldest cyclothems, annotated as PZ1-PZ4 (Fig. 1C). Characteristic features of the present bed arrangement in the uppermost part of the structure are:

- general parallelism of the salt wall and strikes of the beds;

- the occurrence of strongly tectonically disturbed beds, where stratigraphy is difficult to interpret due to complex folding and shearing;

- occurrence of more continuous zones with recognizable stratigraphy, separating the strongly deformed ones (Fig. 2).

The portions of the salt structure with more enigmatic stratigraphy and tectonics are dominantly built of rock salt of the PZ1-PZ2 Zechstein cycles, whereas those with relatively continuous stratigraphy predominantly consist of PZ3 and PZ4 deposits (Figs. 2 and 3 ).

Statistical analysis of the folds by Tarka (1992) showed that they vary in orientation. However, those data included all measurements collected throughout the structure. Subsequent studies revealed that the style of folding depends on location in the structure, that the geometry of the folds is predominantly controlled by lithology, and that there are portions in the KSS where both sedimentary and early tectonic structures are preserved (Burliga, 1996a, b). Although the uppermost part of the
KSS is mainly built of rock salt, clayey salts and salty clays (Figs. 2 and 3 ) and all these rock types are susceptible to deformation, their mutual arrangement as well as the presence of alternations or admixtures of potash minerals, anhydrite or clays strongly influence the fold shapes. The observations carried out within the KSS showed that there are two main lithological associations, which are characterized by different fold patterns. One of these is a multilayer set of rocks with contrasting competence (alternating layers of rock salt and potash as the crucial rock types), the other is a multilayer set of rock salt in which competence variation is insignificant. For the sake of convenience, the first type of the rock setting is referred to as the potash-bearing complex and the second, as the rock salt complex.

The data from the potash-bearing complex were dominantly collected in the PZ3 potash and rock salt complexes (K3 and $\mathrm{Na} 3$, respectively), located between the Main Anhydrite (A3) and the Younger Clay Halite (Na3t) beds (Fig. 2). The data from the rock salt complex were collected throughout the KSS, irrespective of the rock salt age. Fold inspection was carried out at the depth range 450-750 m below the surface. Unfortunately, there are significant limitations in fold analysis in underground galleries. Spacing between the galleries, inaccessibility of gallery roofs and salt dust cover on the walls and roofs are the major obstacles to tracing of folds in three dimensions and measuring their geometric elements. The plunges of fold axes can only be estimated. As a consequence, only qualitative characteris- 


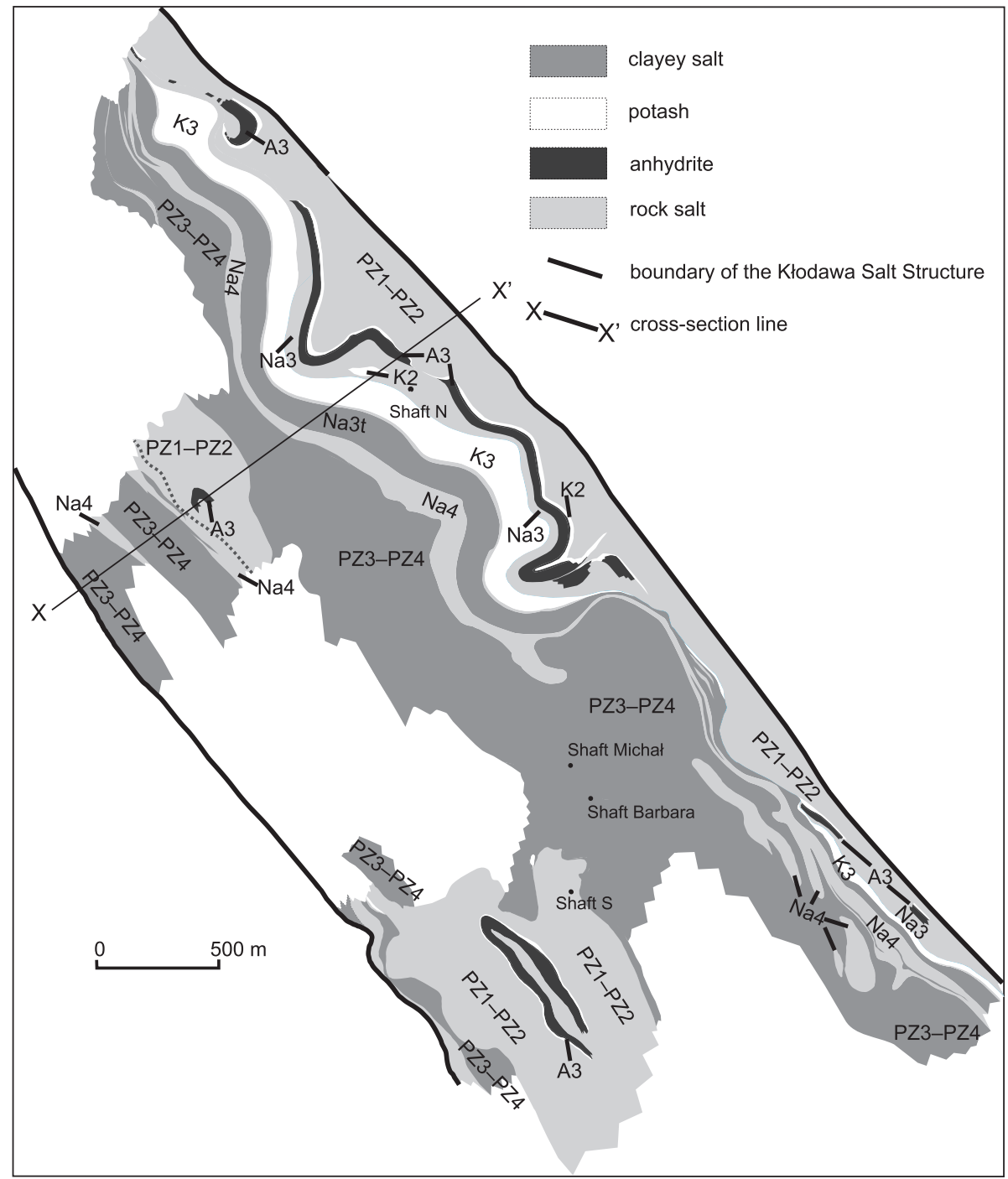

Fig. 2. Lithological map of the Kłodawa Salt Structure at the mining level 600 (based on Burliga et al., 2005)

tics of folds are given below, because no accurate, systematic measurements were possible. The description is based on observations of multiple folds in numerous locations throughout the KSS and illustrated with the most adequate examples.

\section{GEOMETRY AND DISTRIBUTION OF FOLDS IN THE KŁODAWA SALT STRUCTURE}

\section{FOLDS IN THE POTASH-BEARING COMPLEX}

The set of alternating rock salt and potash layers of the PZ3 cycle occurring along the northeastern side of the KSS (Fig. 2) contains abundant folds. Their architecture is shaped by relatively more competent rock salt layers. The most common cross-sections of the folds observed in the mine galleries have relatively constant features: the limbs of the folds are parallel to each other and to the fold axial planes, the hinge zones are narrow, with the outer curvature more gentle than the inner one, the thickness of a salt layer is constant in the limbs and increases in the hinge zones, locally by more than twice (Fig. 4). The axial planes and limbs are dominantly parallel to the bedding. The alternating potash layers are similarly folded. However, due to the low competence of potash, the hinge zone curvature is gentler on the inner side of a fold than on the outer one and the potash layer is several times thicker at the hinge zones than at the limbs. The thickness of a potash layer may be reduced down to zero in the limbs, and in such a case the folds resemble saddle reefs rather than folded layers.

The characteristics given above is typical of isoclinal folds. However, in a few places, salt layers display patterns of extremely flattened ellipses, which suggests that these isoclinal folds represent in fact random sections across sheath folds. Sheath geometry of folds is also indicated by variation in fold axis plunges. The axes measured at hinges of those elliptical cross-sections show opposite plunging directions at angles in the range of $\sim 50$ to $\sim 75^{\circ}$. The scatter of plunges at the noses of the sheath folds prevents determination of the true sheath fold axes with high accuracy, nevertheless these true axes appear 


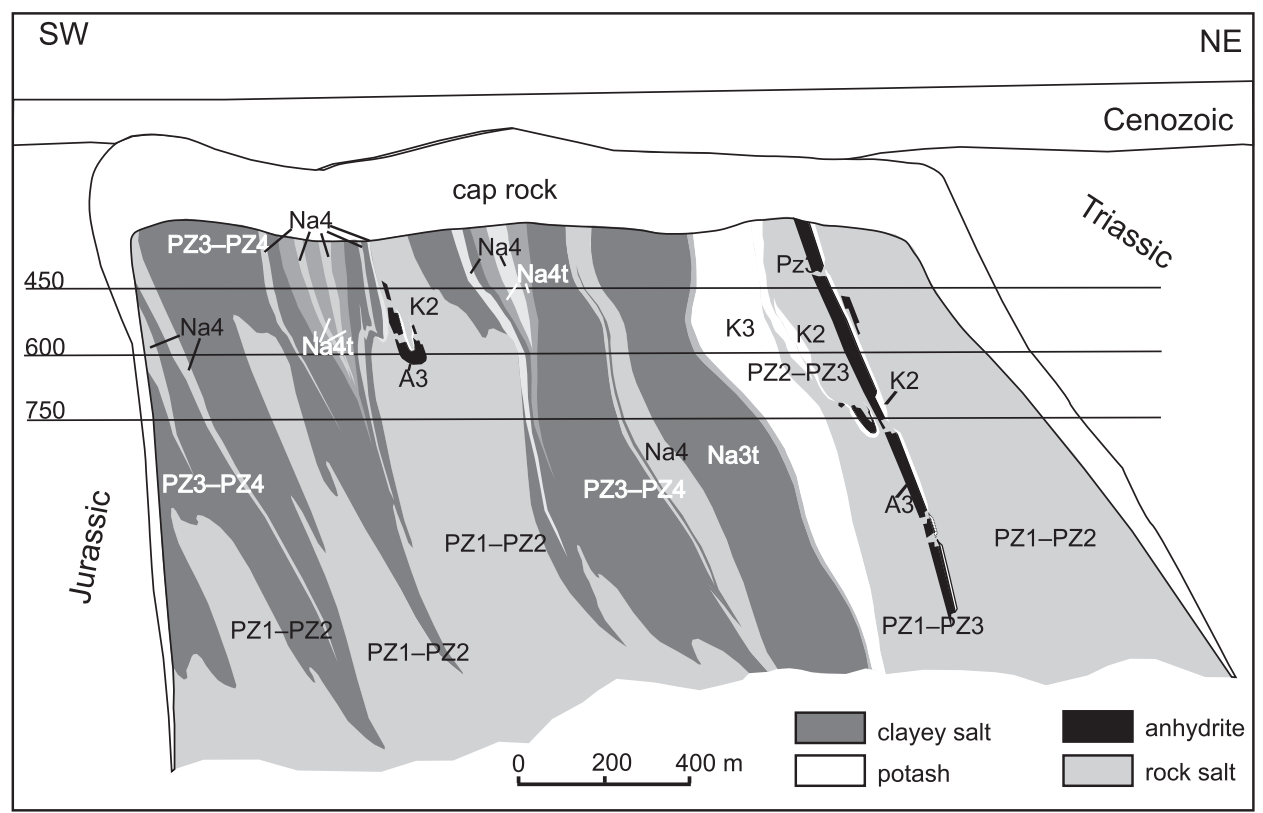

Fig. 3. Geological cross-section across the uppermost part of the Kłodawa Salt Structure

Line of section is indicated in Figure 2 (based on Burliga et al., 2005)

to plunge steeply, in the range of $\sim 60$ to $90^{\circ}$. The amplitudes of folds are enigmatic, due to the small dimensions of the mine galleries. In accessible sections, they exceed $3 \mathrm{~m}$ (average height of a gallery); the upper limit seems, however, to be much higher, in the range of tens of metres. The fold wavelengths vary between tens of centimetres to at least several metres.

In terms of the sheath fold classification proposed by Alsop and Holdsworth (2006), the sheath folds dominantly display cats-eye patterns. Based on a few cases where complete sheath fold cross-sections outcrop, it can by concluded that the $\mathrm{R}_{\mathrm{xy}}$ ellipticity parameter (see Alsop and Holdsworth, 2006; Alsop et al., 2007) can be very high, even over 20 (compare folds in Fig. 4A).

In several locations, superposition of folds is observed. The superposed folds possess the same geometrical features as those described above: their limbs and axial planes tend to be parallel to each other and to the major sedimentary boundaries, their interlimb angle is close to $0^{\circ}$ and the same variation of a layer thickness at limbs and hinge zones is observed. Therefore, most probably these are also sheath folds. Refolding of the older axial planes into sheath folds resulted in the basin-and-dome (elliptical), zig-zag or more complex patterns of folds, noticeable in the walls and roofs of the mine galleries (Fig. 4C).

Folds in the potash-bearing complex are commonly associated with faults and boudinage. The faults are generally parallel to the fold axial planes and limbs as well as to the bedding (at large scale). Thus, they represent detachments or décollements. They can be distinguished exclusively in fold hinges, where they cut across the rock salt layers, displacing fold limbs (Figs. 4B and 5A, C). Commonly, one of the fold limbs is missing in faulted sequences, which may be due either to its distortion or to the high amplitude of the displacement along the fault plane, exceeding the dimensions of mine galleries. If the displacement is small, the fault planes are gently curved at fold hinges and bent upwards (in relation to the stratigraphy). Apart from the fold hinges, faults of this type are not recognizable in the potash-bearing sequence due to the lack of any small-scale tectonic structures typical of faults and due to the absence of distinct fault planes. These faults propagate into potash layers, where they are not distinguishable. Fault planes are folded by superposed folds in places, implying that they are kinematically coeval with the early folds.

Boudinage is developed in rock salt layers interbedded with potash. It becomes more common with increase in potash layer thickness. However, where there is a relative dominance of potash over rock salt the latter are extremely boudinaged and it is not possible to decipher the continuity of individual layers; the whole complex resembles a tectonic melange. Boudinage is developed primarily in fold limbs and rarely in fold hinges. It can affect either sets of layers or only individual layers in a fold limb (Fig. 5B). The boudins and interboud in necks range from a few millimetres to at least several metres in length (observation limited by the dimensions of the galleries). If the boudinage affects individual layers in a fold, it is more intense in layers located away from the fold core. The boudins are noticeable both in the roofs and walls of galleries, which implies that this is a chocolate tablet type of boudinage.

Similar tectonic structures are seen in the potash complex of the second Zechstein cycle (PZ2). The Older Potash (K2) rock salt contains abundant folds of similar geometry to that observed in the $\mathrm{K} 3$ complex. Detachments, boudinage and potash saddle reefs are also present. The major difference between the two potash complexes is that there are dominantly relics of folds in the Older Potash complex. It is worth mentioning that above the stratigraphic tops of both potash complexes weakly deformed beds occur, which contain well-preserved sedimentary structures, e.g. horizons with weakly deformed desiccation polygons and fissures (Burliga, 1996b)

\section{FOLDS IN THE ROCK SALT COMPLEX}

The thickness of individual rock salt layers varies across a range of $\sim 2-60 \mathrm{~cm}$. However, they occur in assemblages up to 

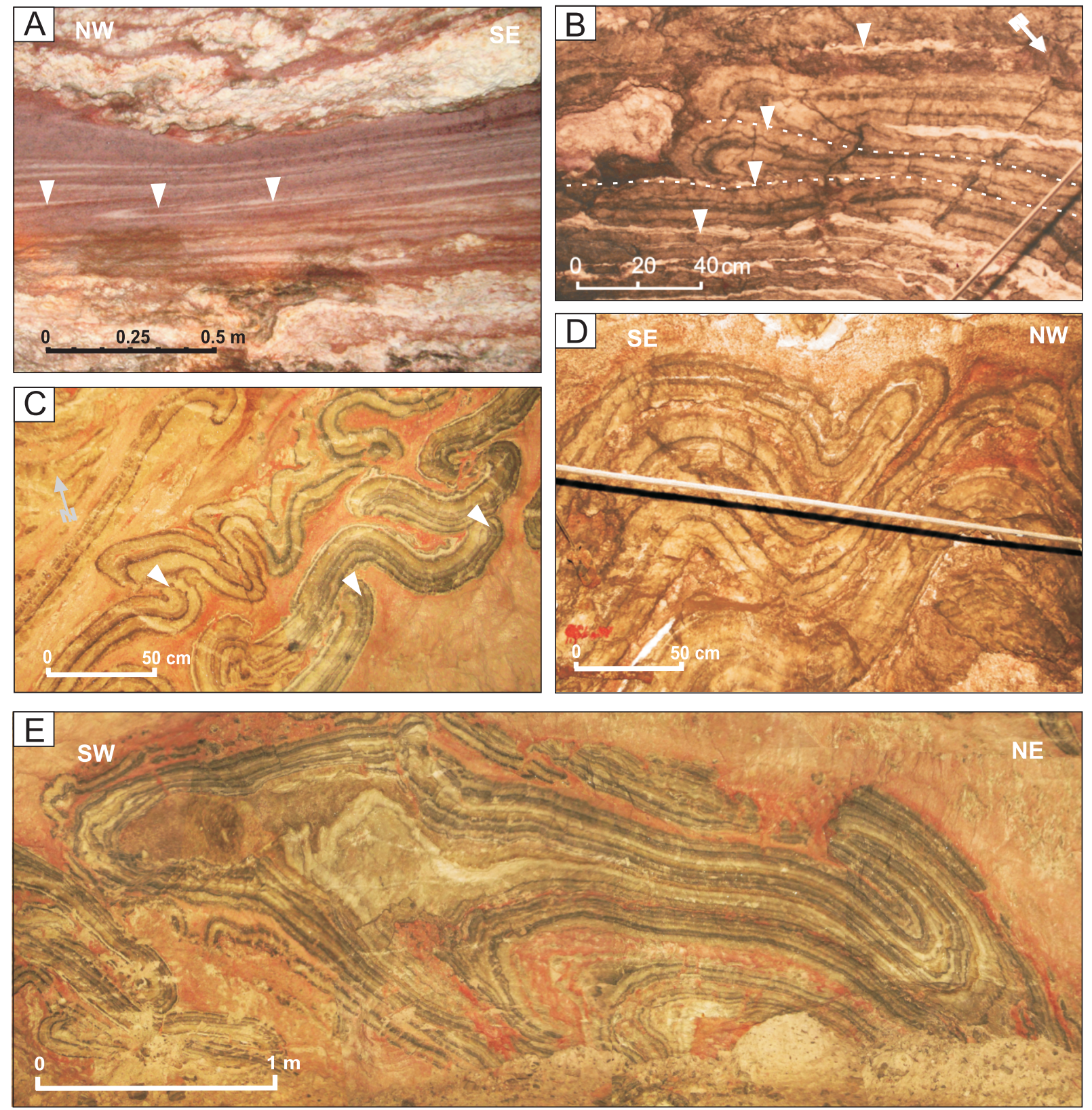

Fig. 4. Folds in PZ3 potash-rich complex

A - extremely flattened sheath folds in a cross-section in the roof of a mine gallery (some folds indicated with arrow); true axis of the fold is perpendicular to this cross-section; B - roof view of a pair of recumbent sheath folds with partly distorted limbs; axial planes are parallel to bedding; dotted lines and arrows indicate selected detachments; $\mathbf{C}$ - progressive salt flow led to development of faults in fold hinges and to separation of fold limbs; D - zig-zag interference pattern in potash complex; potash saddle reefs indicate that some folds may be due to dilation caused by redistribution of potash during deformation; $\mathbf{E}$ - superposition of folds due to progressive flow and redistribution of potash; folds are shaped by rock salt layers in $B, C, D$ and $E$

hundreds of metres thick in places (Fig. 2). This is not the original stratigraphic thickness of the rock salt units but the result of tectonic deformation and repetition of layers, dominantly due to their folding. Layering in thick rock salt complexes of white or pinkish colour is defined by the rhythmic occurrence of thin $(\sim 1-\mathrm{cm}$-thick) laminae of rock salt with dispersed greyish anhydrite (Fig. 6). These laminae do not seem to influence the overall rheology of the rock salt.

Two dominant types of folds are present within the rock salt complexes (Fig. 6). Folds of the first type display similar geometry to those observed in the potash-bearing complex. They have limbs and axial planes parallel to each other and to the main sedimentary boundaries, which makes the fold interlimb angles close to $0^{\circ}$. Also, the thickness of layers is higher in the hinges than in the limbs, and, locally, this contrast in thickness is as high as in potash layers in the previous complex. Since such cross-sections of folds occur both in the walls and roofs of the mine galleries and their axes plunge (dominantly steeply) in opposite directions in adjacent fold hinges, a sheath geometry is also concluded for these folds. As in the potash-bearing complex, limited dimensions of mine galleries prevent assessment of the true amplitude and wavelength of the folds. They certainly 

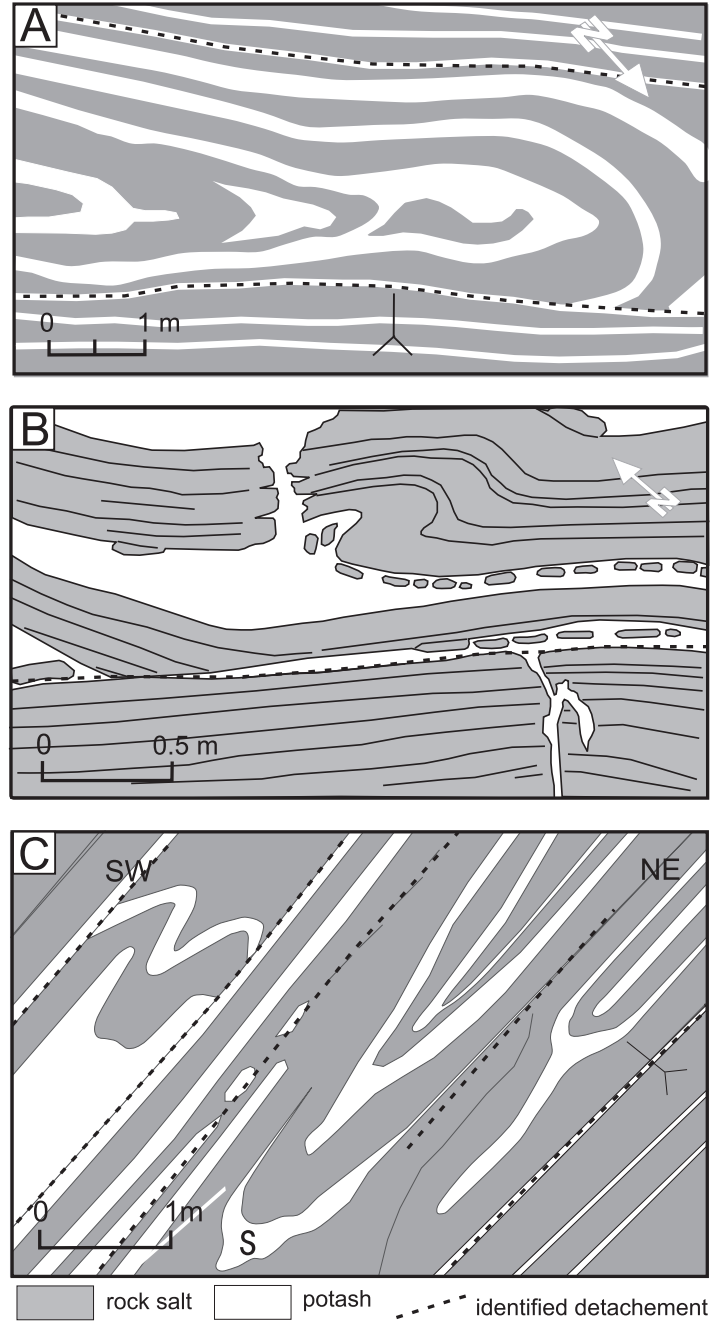

Fig. 5. Folds, boudinage and detachments in $\mathrm{PZ3}$ potash complex

A - a part of a sheath fold inside a set of parallel layers; the bottom limb of the fold is distorted along a detachment; B initial folding of a rock salt bed behind a ramp developed above a detachment; folded layers are boudinaged; this process leads to development of a tectonic melange; directions of tectonic displacement cannot be assessed because there are no meso-scale kinematic indicators; C - a set of folds and detachments (selected detachments are marked with dotted lines) indicates bedding-parallel flow of salts; local angular unconformities along detachments imply that at least some of parallel layers represent in fact limbs of partly distorted folds; saddle reefs (s) point to interlayer slip during flow of salt

exceed $15 \mathrm{~m}$ in height (the average height of large mine chambers), with the width ranging from less than $1 \mathrm{~m}$ to at least several metres. The most characteristic feature distinguishing them from the folds in the potash-bearing complex is the presence of numerous minor, short-wavelength, high-amplitude folds. These folds are best visible in the hinge areas of large folds and they depict variation in asymmetry typical of drag folds. Due to the similarity of their geometry to a seismograph record (note hinges in Fig. 6), these folds are referred to as salt seismograms in the literature dealing with salt (Hartwig, 1923; Schwerdtner, 1966).
Faults parallel to fold axial planes, which displace fold limbs, were also documented in the rock salt complexes. However, they seem to be very scarce. Unlike in potash-bearing complexes, the fault planes do not depict change in inclination at fold hinges; they are completely planar.

Folds of the second type are recognizable primarily in the roofs of large ( $15 \mathrm{~m}$ wide) mine galleries, where they display oval, elliptical or irregular outcrop patterns. Their diameters range from a few metres (the shortest dimension) to at least tens of metres (the longest dimension in plan view). It is difficult to assess their actual dimensions, since only some portions of folds are exposed in the roofs of galleries and the boundaries between neighbouring folds are not distinct (Fig. 7). These folds are hardly noticeable in the gallery wall sections. Irrespective of the fold pattern in the roof, the layering is very steep in the gallery walls, the layers are parallel-to-subparallel and only a local increase in spacing between greyish rock salt laminae provides hints of fold hinge occurrence in the wall. Such an arrangement of layering in the roofs and walls unequivocally points to the sheath geometry of the folds and to a steep-to-vertical plunge of their axes. The amplitudes of these folds remain enigmatic; some of the folds were correlated at several mining levels, over more than $100 \mathrm{~m}$ in vertical section.

The sections across the noses of these sheath folds reveal similar characteristics as seen in the first type of folds in the rock salt complexes: parallel limbs, increase of layer thickness in hinge zones, and secondary folds both in the hinges and limbs (Fig. 6B-D). The secondary folds depict two geometrical types: those visible in the roofs of galleries either display gentle hinges and low amplitude relative to fold width or very sharp, narrow hinges, resembling the seismogram type of folds; those outcropping in the walls show only the latter geometry (Fig. 6B-D). Interestingly, some secondary folds depict reversed drag fold geometry relative to the primary fold hinge (Fig. 7). The most conspicuous feature of these sheath folds is the occurrence of the first type of folds inside their structure. The curved axial planes of the first type of folds are concordant with the geometry of the second type of the sheath folds (Fig. 6C), indicating fold interference and superposition of these large sheath folds on the first type of folds.

The sheath folds developed in the rock salt complexes display all the types of geometries distinguished by Alsop and Holdsworth (2006): cats-eye, bull-eye and analogous-eye patterns (Alsop and Holdsworth, 2006; Alsop et al., 2007). The cats-eye type folds of high ellipticity $\left(R_{x y}\right.$ up to 20$)$ dominate amongst the older fold generation as well as in marginal parts of both the KSS and rock salt complexes. The bull-eye and analogous-eye types occur in the inner portions of thick salt complexes, away from the KSS margins, and they show ellipticity $R_{x y}$ across a wide range of 1 to $>15$. Detailed analysis and interpretation of these superposed folds is very difficult, because of their large dimensions. They can only be roughly restored on map scale, based on variation of bed strikes along individual galleries and sporadic outcrops of their hinges. Such a restoration is particularly uncertain in the case of elliptical folds in which limbs are parallel over long distances. Thus the hinges can easily be omitted (Fig. 7). This is one of the reasons for misinterpretation of the true thickness of rock salt beds in the KSS. The difficulty in distinguishing hinges in the folded rock salt complex in galleries led to the assumption that these beds are not internally deformed and represent a primary stratigraphic sequence (Werner et al., 1960; Charysz, 1973; Tomassi-Morawiec et al., 2007). The axial planes of elliptical superposed folds are locally bent on large scale, which suggests the presence of a yet younger fold generation, also with vertical or sub-vertical axes (Fig. 7). 

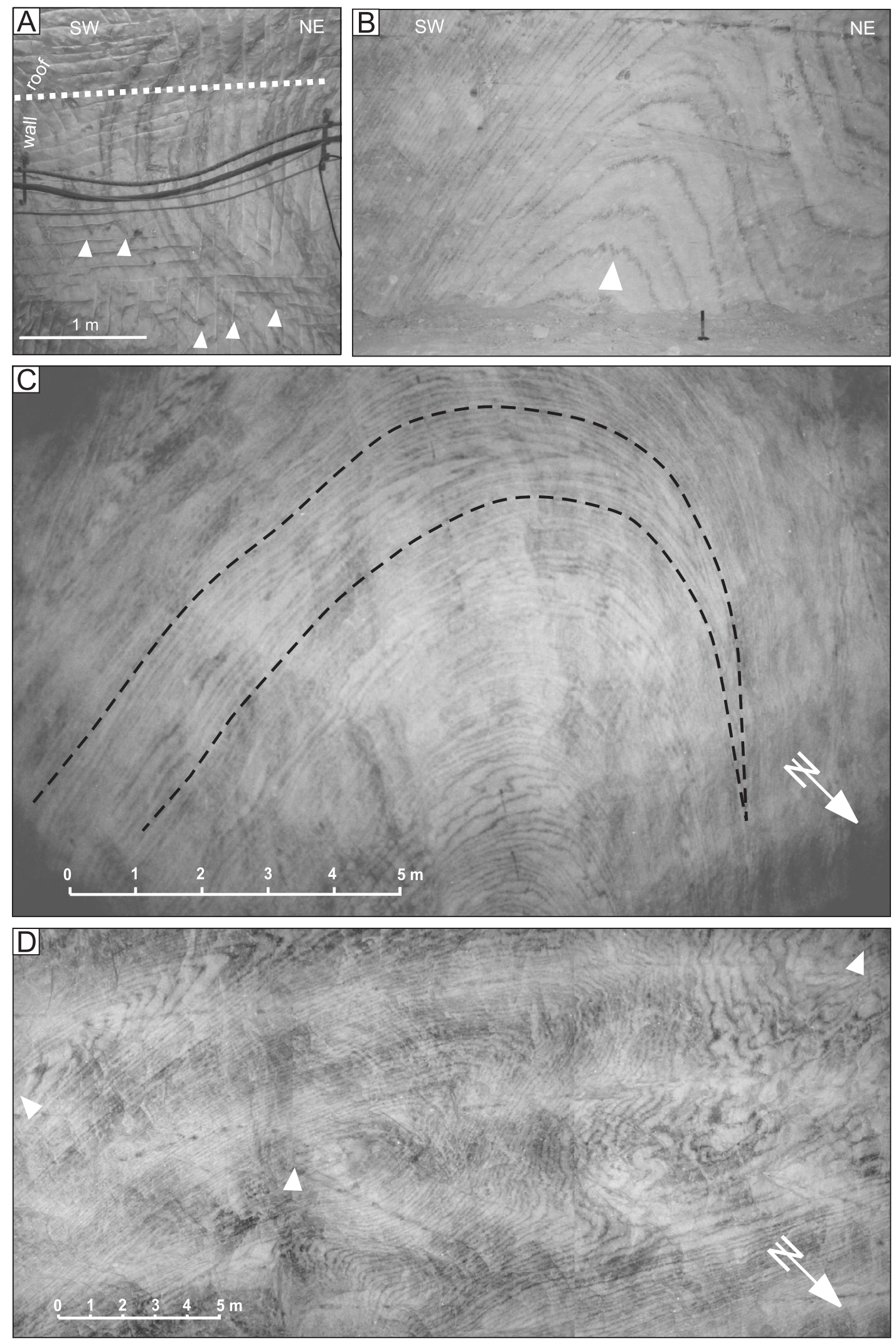

Fig. 6. Folds in rock salt complexes

A - steep, simple sheath folds in the PZ4 rock salt bed; arrows indicate selected hinges in the gallery wall; B - nose of a superposed upright sheath fold in the PZ1-PZ2 salt complex (wall view, hammer for scale); C - a superposed fold in the PZ1-PZ2 complex (roof of an excavation chamber); note refolded early folds inside the oval superposed fold; $\mathbf{D}$ - elliptical patterns of superposed folds in the roof of a chamber in the PZ1-PZ2 rock salt complex; irregularities in fold shape are due to variation in the rate of salt flow and to local dilation; minor folds at fold hinges in $A, B, C$ and $D$ are the secondary shear folds, referred to as salt seismograms 


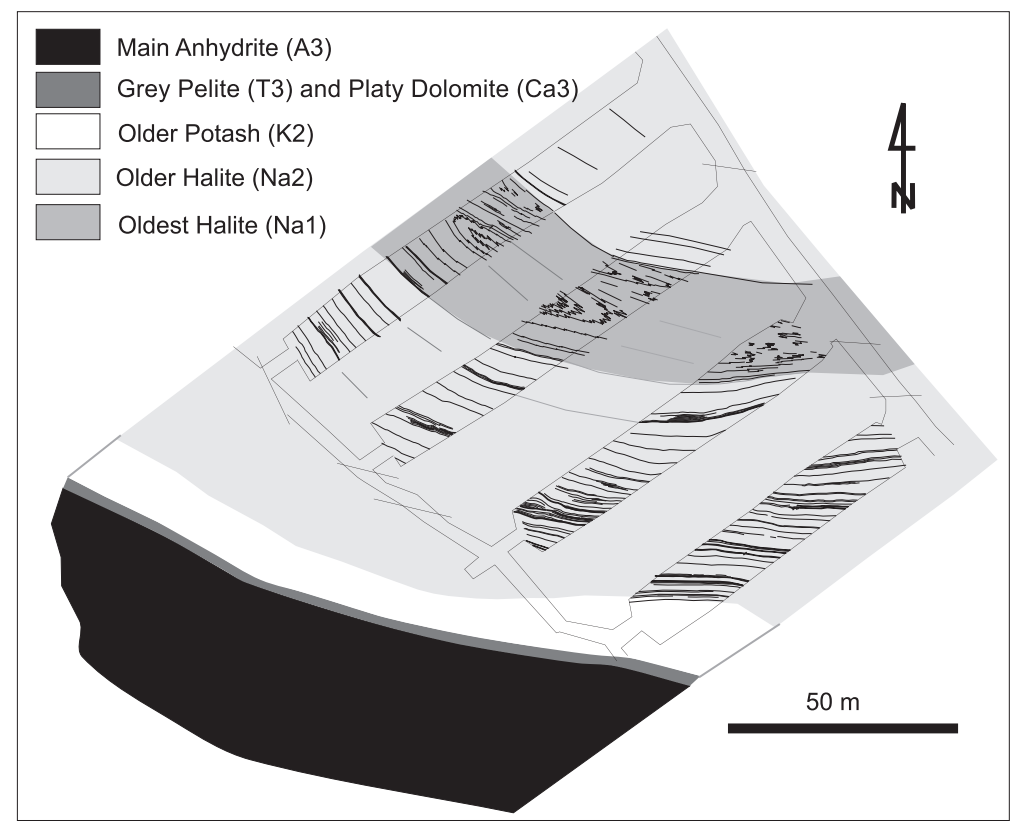

Fig. 7. Superposed upright sheath folds in the PZ1-PZ2 rock salt complex are noticeable only in cases where gallery roof or walls cross-cut their noses

Away from the fold noses, the layering is apparently parallel and not disturbed by salt flow

It is important to note that the first type of sheath folds occurs in the rock salt of every Zechstein cycle (PZ1-PZ4 rock salt). The superposed folds are identified in rock salt complexes of the PZ1 and PZ2 cycles and they commonly incorporate rock salt of these two oldest cycles. Another characteristic feature is that there is incomplete stratigraphy in the areas of superposed fold occurrence: the shale-carbonate-sulphate series which originally separated PZ1 and PZ2 rock salt is typically absent and the rock salts of the two cycles are welded, being barely stratigraphically separable. It is possible that superposed upright sheath folds also occur in thick complexes of PZ4 rock salt locally. However, it cannot be convincingly proved, because the areas of possible superposed fold occurrence in PZ4 rock salt are intersected by few narrow galleries and the geometry of large scale folds is not known.

\section{DISCUSSION}

The presence of superposed folds within salt complexes of the KSS indicates two major phases of folding. The older phase is recorded by sheath folds of relatively simple geometry, which have bedding-parallel, planar axial surfaces and flattened, elliptical outcrop patterns (see also Burliga, 1996a). The younger phase of folding is reflected by sheath folds possessing more oval or irregular outcrop patterns and containing refolded, older folds (Fig. 6C). The resulting geometry of folds enables to draw some conclusions on folding mechanisms. It seems that the present fold patterns originated due to a combination of several processes which slightly differed between the potash-bearing and rock salt complexes.

Indications on the early stage of folding of the evaporite succession are best recorded in the potash-bearing complex, in which simple sheath folds are very common. The initial stage of fold development is illustrated in Figure $5 \mathrm{~B}$, where the transition from non-deformed layers to folded ones is noticeable (see also Burliga, 1996a). Alas, the limited area of observations does not permit to determine unequivocally what causes a layer to fold. The bending of the layer appears behind a sort of a ramp, which is initiated in a layer representing stratigraphically older unit. The nature of the ramp remains ambiguous - it either resulted from folding of the underlying layer or from a detachment which developed below this layer. A characteristic feature noticeable in this figure is that the height of folds in layers occurring closer to the ramp is higher than that of those situated away from the ramp. The hinges of folds in rock salt layers shown in Figures $4 \mathrm{C}$ and $5 \mathrm{~A}, \mathrm{C}$ are pulled apart and the space between them is filled with less competent potash in the form of saddle reefs. The above features are typical of folds developing due to flexural-slip folding and flexural-flow folding, which are specific for layered rocks units, with contrasting competence between the layers. The extreme susceptibility of carnallite (the main mineral in potash layers) to recrystallisation under stress (Urai, 1983) favours flexural-flow folding as the dominant mechanism of fold development. On the other hand, the boudinage and bed-parallel detachments also point to a significant role of shearing during folding and to at least semi-brittle deformation of some salt layers. Thus, the slip along the detachments and bed boundaries could assist salt flow locally. As a consequence, the combination of layer-parallel flow and shearing led to the development of sheath folds. Such a geometry most probably resulted from differentiation of the rate of salt flow between layers, e.g. from random development of detachments and boudinage, which caused perturbations in the salt flow. The detachments cut through fold hinge zones, enabling localized, easier displacement of fold limbs relative to each other. The consistency in fold vergence and geometry of detachments suggests that these structures originated in a stable stress field, and that their development was primarily controlled by gravity (Burliga, 1996a).

Similar fold evolution can be assumed for the older sheath folds developed within the rock salt complexes. As there is no rheological contrast between the layers, most probably flow was the initial folding mechanism in this complex. The significant imprint of shearing on the flow and folding is reflected by the development of minor folds, i.e. salt seismograms, which obtained their geometry primarily due to simple shearing (Balk, 1949; Tarka, 1992). Planar axial surfaces concordant to bedding and flattened-ellipse patterns of fold cross-sections indicate that tectonic transport was controlled by bed arrangement also in the rock salt complexes.

The concordance between the geometry of axial surfaces of the older folds and the geometry of the superposed folds, the upright arrangement of the axial surfaces of these two fold generations as well as the occurrence of basin-and-dome fold interference patterns suggest that the axial surfaces of the older folds were originally perpendicular to their present dip (Fig. 6). It is therefore concluded that the first folding phase resulted in recumbent sheath folds which developed prior to diapirism. Consequently, in order to interpret the original, early direction of tectonic transport one has to refer the older sheath folds and associated detachments to (sub)horizontal layering. The direction of salt flow is indicated by the orientation of sheath fold axes and by the geometry of detachments in fold hinges. The studies carried out by the author in potash-bearing complexes showed that 
using stereographic projection and the trend of the KSS (NW-SE direction) as the axis of bed rotation to a horizontal position, sheath fold axes and displacements congruently point to eastward-westward direction of flow of salt masses, with deflections to the north and south, prior to diapirism (Burliga, 1996a). The majority of the older sheath fold axes in rock salt complexes also trend E-W, with deflection to $\mathrm{N}$ and $\mathrm{S}$, after rotation of the axes to a horizontal position.

The occurrence of recumbent sheath folds in stratiform rock salt beds was recently documented in marginal parts of the Polish Zechstein Basin (Burliga, 2007; Wilkosz et al., 2012). This indicates that flow and folding of salt beds, in fact, begins long before the initiation of salt pillow or diapir initiation and that probably only a minute inclination of beds triggers salt flow. Also recently, gravity-driven sliding, flow and folding of stratiform beds have been well-documented by seismic data in salt basins located on continental slopes (Davison et al., 2012; Fiduk and Rowan, 2012; Fort and Brun, 2012; Adam and Krezsek, 2012; Quirk et al., 2012; Strozyk et al., 2012). These data show that inclined salt beds flow downwards in response to gravity and sediment loading and that the gravity-driven sliding and flow leads to deformation of the evaporite sequence as well as an increase in its total thickness down the slope, prior to diapirism. In the case of the KSS, the flow of salt masses in a stratiform bed arrangement was triggered by a combination of factors, among which the most important were activity of the basement (sub-salt) fault, regional inclination of beds due to a variable rate of subsidence in the basin and sediment load above the Zechstein strata. These factors forced redistribution of the salt mass: first, flow and gliding of salt from the rising fault wall towards the subsiding wall of the fault, then, after weakening of the cover above the basement fault, towards the rising salt ridge that formed above the basement fault. The direction of flow was determined by the basement fault geometry - in either case salt migrated perpendicularly to the strike of the fault and this is reflected in the consistent orientation of the early fold axes (with a dominantly NE-SW plunge after rotation of beds to horizontal). The north-eastwards regional inclination of the Zechstein evaporite beds was also induced by faulting (step-like normal faults in the basement), which enhanced variable subsidence in the Permian-Mesozoic basins in Poland the highest NE of the KSS from the Late Permian until the Late Cretaceous (Dadlez et al., 1995; Dadlez, 1997, 1998). The stratiform beds containing recumbent sheath folds were subsequently refolded during the upward flow of salt in a salt ridge stem. The initiation of the rise of the KSS is dated back to the late Early Triassic (Burliga, 1997). This evolution of folds is schematically illustrated in Figure 8. The new generation of folds depicts mature sheath shapes and heights of tens or, more probably, hundreds of metres. Their geometry is apparently determined by the arrangement of more competent rock complexes (thick anhydrite and clay-rich rock salt beds) and by the KSS outer walls. Constricted superposed sheath folds with elliptical cross-sections occur close to these structural elements, whereas folds that are more oval and circular in cross-section were documented within the inner portions of thick rock salt complexes. Because these folds show similar geometrical features to folds developed during horizontal flow, similar mechanisms of folding can be deduced for them, i.e. progressive flow of rock salt during shearing.

The zig-zag fold interference patterns in the potash-bearing complex (Fig. 4C) hint at other possible scenarios of refolding. These superposed folds could develop due to progressive folding of layers in any bed arrangement. Alternatively, such refolding could result from local volumetric changes in the salt complex mass. The redistribution of potash minerals in response to interaction of folding, boudinage, shearing, recrystallisation and solution-precipitation processes is abundantly observed in the potash-bearing complex. The dilation of the salt complex is also the most plausible explanation of complex and irregular fold interference patterns which locally occur both in the potash and rock salt domains (Fig. 6D).

There is no evidence on curtain folding of the early recumbent folds due to feeding the stem of the KSS with salt from the surrounding source layers, as interpreted by Talbot and Jackson (1987) for oval diapirs. Large upright superposed sheath folds contain only fossil recumbent sheath folds in their structure. Large-scale bending of the elongated superposed sheath folds as seen in Figure 7 is the only possible indication of curtain folding of the salt succession. These large open folds have (sub)vertical fold axes and axial planes. They could, however, have originated due to diachronous and non-uniform supply of salt from below. On the other hand, it is equally possible that the observed bending of the superposed folds results from local dilation at some stage of the salt ridge rise.

Superposition of folds is most common in rock salt complexes, implying that the upward flow of evaporites was domi- 
nantly accommodated by rock salt. The rock salt complexes formed second order diapirs within the KSS (spines sensu Kupfer, 1976), separated by relatively competent rock complexes which were passively carried by salt and sheared. These more competent rock domains contain became either boudinaged or contain only early sheath folds, developed at the stratiform bed arrangement. The folds are more common in clayey salts. However, there is also a large-scale syncline delineated by the Main Anhydrite (A3) bed in the SW part of the mining area (Fig. 2), located between two thick, complexly folded rock salt domains. This anhydrite syncline had to originate when the beds were (sub)horizontal, because it contains different sets of tension gashes indicative of the reversal of direction of shearing along the limbs of the syncline (Burliga, 1994). The recorded change in direction of shearing seems to relate to rotation of the limbs from horizontal to vertical during the diapiric rise of the KSS. The above interpretation is also supported by observations carried out by the author in stratiform salt succession in the marginal parts of the Zechstein basin, where there are anhydrite beds folded into recumbent sheath folds of similar geometry (Burliga, 2007). Interestingly, the potash-bearing complexes in the KSS also contain abundant early tectonic structures, which are refolded only locally. Thus, it indicates that potash complexes also played a minor role in the upward flow of salt masses.

Figure 6 shows that the style of folding in welded PZ1 and PZ2 rock salt beds significantly differs, being relatively more complex in the PZ1 rock salt bed (Fig. 6A vs. 6C, D). This implies that independent systems of recumbent sheath folds originated in the PZ1 and PZ2 rock salt beds prior to their welding. Independent fold systems also developed in PZ3 and PZ4 rock salt. All these observations point to significant role of more competent layers in the Zechstein salt deformation. At the early stage of salt flow, at the stratiform bed arrangement, the deformation was partitioned into individual rock salt complexes and they could fold together only after thinning or disintegration of the competent rock interlayers (e.g., due to boudinage). The most significant competent rock barrier in the Zechstein formation relates to the thick A3 anhydrite bed, separating deposits of PZ1 and PZ2 cycles from those of PZ3 and PZ4 cycles. The two older rock salt complexes are commonly welded and they are barely distinguishable between each other in the KSS, due to their joined folding into large-scale sheath folds. Contrastingly, there is no single location in the KSS where such a perfect welding of the younger rock salt complexes could be observed and they are not incorporated in large scale superposed folding together with the PZ1 and PZ2 rock salt. If the A3 anhydrite bed is missing due to large-scale boudinage, a distinct tectonic boundary (a fault or narrow shear zone) typically separates the older and younger salt complexes and both complexes display variable internal tectonic structures. Thus, the A3 anhydrite bed divided the Zechstein series into two domains: the older, which is complexly folded and the younger in which early tectonic structures dominate and superposed sheath folds are rare. The older complex pierced through the younger one as second order diapirs, separating synclinoria built of PZ3 and PZ4 complexes (Figs. 2 and 3 ). A conceptual model of this sequence of events is shown in Figure 9.

\section{CONCLUSIONS}

The studies carried out in the uppermost part of the KSS show that there are several fold generations documenting various stages of the Zechstein salt deformation. Most of the folds originated prior to the diapiric rise of the KSS and they are preserved in domains which were relatively passive during the upward flow of salt masses. The domains of active rise of salt masses contain large upright superposed folds with refolded
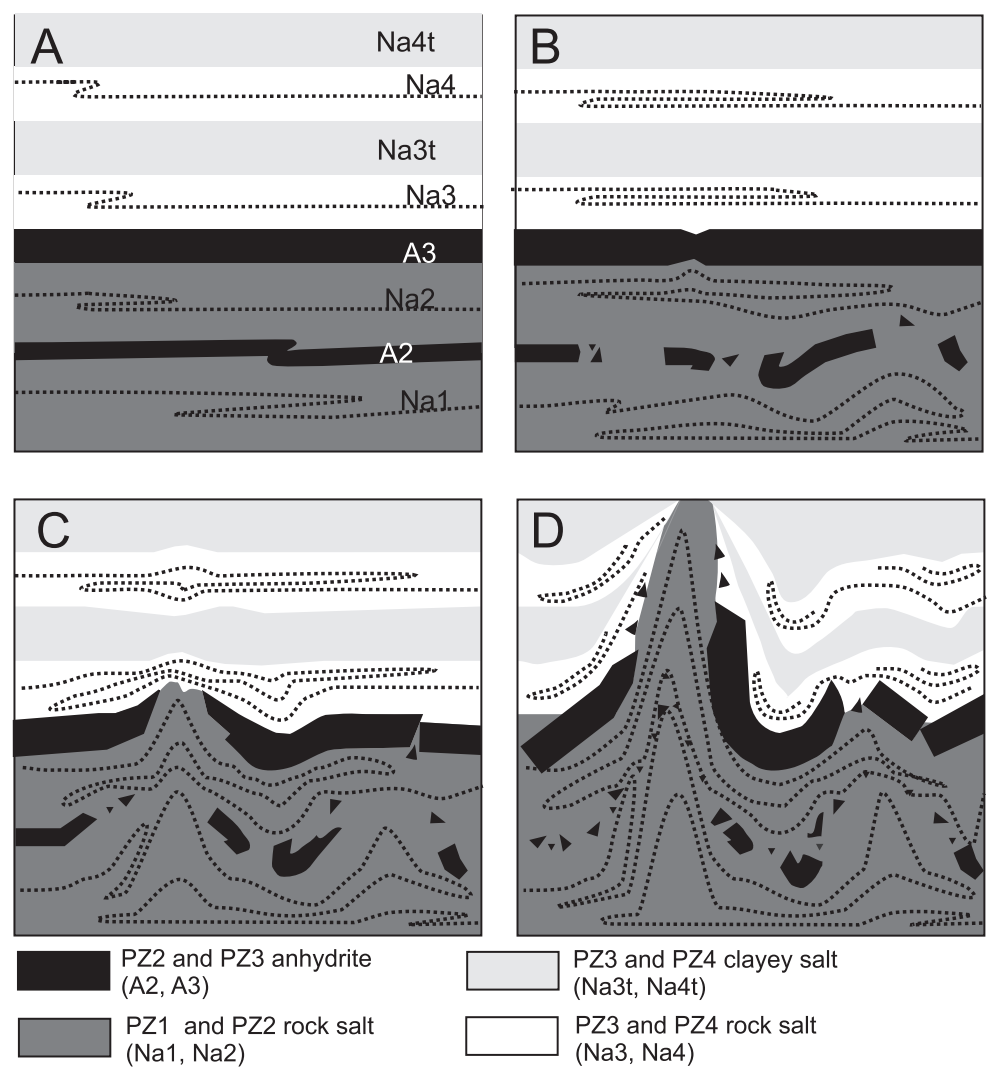

Fig. 9. Conceptual model of heterogeneous deformation of the Zechstein series in the Kłodawa Salt Structure area

A - flow of salt and folding was diachronous; it was initiated in the most deeply buried salt beds, then, successively, in the younger ones; generations of folds developed independently in each salt bed; $\mathbf{B}$ - the flow of salt led to boudinage and disintegration of thin competent beds (sulphates, shales and carbonates; marked as A2 for simplicity in the scheme) which originally separated the PZ1 and PZ2 rock salt beds; this process resulted in welding of the PZ1 and PZ2 rock salt beds; C - the boudinage of the thick A3 complex (sulphates, shales and carbonates separating the PZ2 and PZ3 rock salt complexes) enabled upward flow of older rock salt complexes into the interboudin necks; the interboudin necks delineated the location of the subordinate diapirs, i.e. the areas of active upward flow of salt masses; $\mathbf{D}$ - withdrawal of salt to secondary diapirs enhanced sinking of anhydrite beds and PZ3-PZ4 complexes; this process led to development of angular unconformities between the PZ1-PZ2 and PZ3-PZ4 complexes; the lithostratigraphy is shown in figure $A$ 
recumbent sheath folds in their structure. The fold interference pattern is therefore a distinguishing feature in evaluation of relative activity in various portions of the salt structure. The passive domains contain abundant fossil recumbent sheath folds and they typically border with beds hosting weakly deformed sedimentary structures. Both the early and superposed folds display sheath geometry. In case of the early sheath folds, they are extremely flattened, with limbs parallel to bedding and minor shear folds in fold hinges, whereas the superposed sheath folds are elliptical, oval or irregular in cross-sections. It is very likely that variation in fold geometry and some interference patterns result from local, diachronous dilation of rock mass in the KSS, which was triggered by a variety of factors, e.g. difference in rate of salt flow, mineral transformation or salt dissolution and precipitation.

The geometrical relationships between the early and superposed folds indicate that the first originated in a stratiform salt succession during lateral flow of evaporitic beds, independently in each rock salt complex, whereas the latter developed exclusively in domains with increased rock salt thickness during the upward flow of a rock salt mass in the KSS stem. Lateral flow and gliding of salt complexes led primarily to boudinage of more competent beds, welding of PZ1 and PZ2 salt beds and to local increase in rock salt thickness due to folding and overthrusting of beds. Once welded, the PZ1-PZ2 salt beds could fold together. Because the PZ3 and PZ4 rock salt beds are not incorporated in large, upright superposed folds, it points to that the A3 anhydrite bed constituted a significant mechanical barrier in the Zechstein series. This bed separated the Zechstein series into two complexes, which were heterogeneously internally folded. The older complex, built of PZ1 and PZ2 deposits, was intensely deformed both during lateral and vertical flow of salt. Progressive flow resulted in distortion of more competent beds and in superposition of folds during the rise of the salt ridge. This complex correlates with domains of active upward flow of salt masses and development of secondary diapirs in the KSS. The younger complex, originally overlying the A3 anhydrite bed, contains early tectonic and sedimentary structures, and the beds maintain a stratigraphic sequence. The younger complex was relatively passive during the upward flow of the rock salt mass, being folded into large scale synclinoria, separated by second order diapirs.

The early (originally recumbent) sheath folds occur in every rock salt complex and they show similar geometry, irrespective of the rock salt age. The fold geometry only differs in complexes interlayered with potash. A high competence contrast between the rock salt and potash led to flexural-flow folding of beds, which was probably assisted by interlayer slip due to shearing. These processes resulted in the development of potash saddle reefs in fold hinges (instead of minor shear folds), as well as in common development of detachments and boudinage. A similar geometry of simple sheath folds throughout the Zechstein complex indicates that the folds developed in response to uniform mechanisms operating in a stable stress field and bed arrangement. The early sheath folds display dominantly cats-eye patterns and very high ellipticity $R_{x z}$ of up to $\sim 20$, whereas the folds developed during the upward salt flow show a wider range of ellipticity $R_{x z}$, between 1 and $>15$. The lower ellipticity of superposed folds is observed in inner portions of thick rock salt complexes. The early sheath folds were relatively inactive during the upward flow of the salt mass; they only rotated to vertical during steepening of beds in the KSS stem and modified by shearing. The studies carried out within the uppermost part of this structure showed that despite diapiric rise and several $\mathrm{km}$-long lateral and upward migration of the Zechstein sequence, there are tectonic structures which evidence both early and late stages of the KSS development.

Acknowledgments. I am extremely grateful to the "Kłodawa" Salt Mine authorities for the permission to investigate the interior of the KSS and, in particular, to the former and present geological staff of the mine: G. Misiek, P. Kolonko, R. Chęciński, A. Sobiś and J. Chojnacki, who helped in the underground studies. I also thank J.-P. Callot and an anonymous reviewer whose remarks helped to improve the manuscript. The data presented in this paper were collected due to financial support granted by the Polish Ministry for Science and Higher Education and, partly, due to grants of the Institute of Geological Sciences of University of Wrocław.

\section{REFERENCES}

Adam, J., Krezsek, C., 2012. Basin-scale salt tectonic processes of the Laurentian Basin, Eastern Canada: insights from integrated regional 2D seismic interpretation and 4D physical experiments. Geological Society Special Publications, 363: 331-360.

Alsop, G.I., Holdsworth, R.E., 2006. Sheath folds as discriminators of bulk strain type. Journal of Structural Geology, 28: 1588-1606.

Alsop, G.I., Holdsworth, R.E., McCaffrey, K.J.W., 2007. Scale invariant sheath folds in salt, sediments and shear zones. Journal of Structural Geology, 29: 1585-1604.

Balk, R., 1949. Structure of Grand Saline salt dome, Van Zandt County, Texas. AAPG Bulletin, 33: 1791-1829.

Burliga, S., 1994. Tension gashes in the Platy Dolomite from the south-western part of the Kłodawa Salt Dome - kinematic implications (in Polish with English summary). Przegląd Geologiczny, 42: 99-102.

Burliga, S., 1996a. Implications for early basin dynamics of the Mid-Polish Trough from deformational structures within salt deposits in central Poland. Geological Quarterly, 40 (2): 185-202.
Burliga, S., 1996b. Kinematics within the Kłodawa salt diapir, central Poland. Geological Society Special Publications, 100: 11-21.

Burliga, S., 1997. Evolution of the Kłodawa Salt Dome (in Polish with English summary). In: Salt Tectonics in the Kuiavian Region (ed. S. Burliga): 1-12. WIND-J.Wojewoda, Wrocław.

Burliga, S., 2007. Internal structure of subhorizontal bedded rock salt formation in the area of Sieroszowice - meso- and microstructural investigations. Gospodarka Surowcami Mineralnymi, 23: $51-64$.

Burliga, S., Janiów, S., Sadowski, A., 2005. Mining perspectives in the Kłodawa Salt Mine considering modern knowledge on tectonics of the Kłodawa Salt Structure (in Polish with English summary). Technika Poszukiwań Geologicznych Geosynoptyka i Geotermia, 4: 17-25.

Burliga, S., Koyi, H.A., Chemia, Z., 2012. Analogue and numerical modelling of salt supply to a diapiric structure rising above an active basement fault. Geological Society Special Publications, 363: 395-408. 
Callot, J.P., Letouzey J., Rigollet, C., 2006. Stringers Evolution in Salt Diapirs, Insight from Analogue Models. AAPG International Conference and Exhibition, Perth, Australia

Charysz, W., 1973. Zechstein stage of Younger Salts (Z3) in Kujawy region (in Polish with English summary). Prace Geologiczne PAN, 75.

Dadlez, R., 1997. Epicontinental basins in Poland: Devonian to Cretaceous - relationship between the crystalline basement and sedimentary infill. Geological Quarterly, 41 (4): 419-432.

Dadlez, R., 1998. Devonian to Cretaceous epicontinental basins in Poland: relationship between their development and structure (in Polish with English summary). Prace Państwowego Instytutu Geologicznego, 165: 17-30.

Dadlez, R., Narkiewicz, M., Stephenson, R.A., Visser, M.T.M., Wees, J.-D. van, 1995. Tectonic evolution of the Mid-Polish Trough: modelling implications and significance for central European geology. Tectonophysics, 252: 179-195.

Davison, I., Bosence, D., Alsop, G.I., Al-Aawach, M.H., 1996. Deformation and sedimentation around active Miocene salt diapirs on the Tihama Plain, northwest Yemen. Geological Society Special Publications, 100: 23-39.

Davison, I., Anderson, L., Nuttall, P., 2012. Salt deposition, loading and gravity drainage in the Campos and Santos salt basins. Geological Society Special Publications, 363: 159-173.

Fiduk, J.C., Rowan, M.G., 2012. Analysis of folding and deformation within layered evaporites in Blocks BM-S-8 and -9 , Santos Basin, Brasil. Geological Society Special Publications, 363: 471-487.

Fort, X., Brun, J-P., 2012. Kinematics of regional salt flow in the northern Gulf of Mexico. Geological Society Special Publications, 363: 265-287.

Hartwig, F., 1923. "Salt-Seismogramme", ihre tektonische und praktische Bedeutung. Kali, 17: 193-197.

Hoy, R.B., Foose, R.M., O'Neill, B.J., 1962. Structure of Winnfield salt dome, Winn Parish, Louisiana. AAPG Bulletin, 46: 1444-1459.

Jackson, M.P.A., 1985. Natural strain in diapiric and glacial rock salt, with emphasis on Oakwood Dome, East Texas. University of Texas at Austin, Bureau of Economic Geology, Report of Investigations, 143.

Jackson, M.P.A., Cornelius, R.R., 1987. Stepwise centrifuge modeling of the effects of differentional sedimentary loading on the formation of salt structures. In: Dynamical Geology of Salt (eds. I. Lerche and J.J. O'Brien): 163-253. Academic Press Inc.

Jackson, M.P.A., Cornelius, R.R., Craig, C.H., Gansser, A., Stöcklin, J., Talbot, C.J., 1990. Salt diapirs of the Great Kavir, Central Iran. GSA Memoir, 177.

Krzywiec, P. 2004. Triassic evolution of the Kłodawa Salt Structure: basement-controlled salt tectonics within the Mid-Polish Trough (Central Poland). Geological Quarterly, 48 (2): 123-134.

Krzywiec, P., 2006. Structural inversion of the Pomeranian and Kuiavian segments of the Mid-Polish Trough - lateral variations in timing and structural style. Geological Quarterly, 50 (1): 151-168.

Kupfer, D.H., 1962. Structure of Morton Salt Company mine, Weeks Island salt dome, Louisiana. AAPG Bulletin, 46: 1460-1467.

Kupfer, D.H., 1976. Shear zones inside Gulf Coast salt stocks help to delineate spines of movement. AAPG Bulletin, 60: 1434-1447.

Kupfer, D.H., 1989. Internal kinematics of salt diapirs: discussion. AAPG Bulletin, 73: 939-942.

Lokhorst, A., ed., 1998. NW European Gas Atlas. Haarlem (NITG-TNO).

Misiek, G., 1997. Stratigraphy of Zechstein deposits in the Kłodawa Salt Dome. In: Salt Tectonics in the Kuiavian Region (ed. S. Burliga): 20-23. WIND-J.Wojewoda, Wrocław.

Quirk, D.G., Schřdt, N., Lassen, B., Ings, S.J., Hsu, D., Hirsch, K.K., Nicolai, C. von, 2012. Salt tectonics on passive margins: examples from Santos, Campos and Kwanza basins. Geological Society Special Publications, 363: 207-244.

Richter-Bernburg, G., 1980. Salt tectonics, interior structures of salt bodies. Bulletin des Centres de Recherches ExplorationProduction Elf-Aquitaine, 4: 373-393.

Schwerdtner, W.M., 1966. Preferred orientation of halite in a "salt seismogram". In: Proceedings of the Second Symposium on Salt, Northern Ohio Geological Society, Cleveland: 70-84.

Strozyk, F., Gent, H. van, Urai, J., Kukla, P.A., 2012. 3D seismic study of complex intra-salt deformation: an example from the Upper Permian Zechstein 3 stringer, western Dutch offshore. Geological Society Special Publications, 363: 489-501.

Talbot, C.J., Jackson, M.P.A., 1987. Internal kinematics of salt diapirs. AAPG Bulletin, 71: 1068-1093.

Talbot, C.J., Jackson, M.P.A., 1989. Internal kinematics of salt diapirs: reply. AAPG Bulletin, 73: 946-950.

Talbot, C.J., Jackson, M.P.A., 1991. A glossary of salt tectonics. University of Texas at Austin, Bureau of Economic Geology, Geological Circular: 91-4.

Tarka, R., 1992. Tectonics of some salt deposits in Poland based on mesostructural analysis (in Polish with English summary). Prace Państwowego Instytutu Geologicznego, 137.

Tomassi-Morawiec, H., Czapowski, G., Borneman, O., Schramm, M., Tadych, J., Misiek, G., Kolonko, P., Janiów, S., 2007. Standard bromide profiles for Zechstein salt deposits of Poland: salts of PZ2 (Z2) cycle in the Kłodawa salt mine. Gospodarka Surowcami Mineralnymi, 23: 103-116.

Urai, J.L., 1983. Deformation of wet salt rocks. Ph.D. thesis, University of Utrecht.

Werner, Z., Poborski, J., Orska, J., Bakowski, J., 1960. A geological and mining outline of the Kłodawa salt deposits (in Polish with English summary). Prace Instytutu Geologicznego, 30: 467-494.

Wilkosz, P., Burliga, S., Grzybowski, Ł., Kasprzyk, W., 2012. Comparison of internal structure and geomechanical properties in horizontally layered Zechstein rock salt. In: Mechanical Behavior of Salt VII (eds. P. Bérest, M. Ghoreychi, F. Hadj-Hassen and M. Tijani): 89-96. CRC Press, Taylor and Francis Group, Leiden. 